\title{
Study of urinary acidification in patients with idiopathic hypocitraturia
}

N.C. Araújo and

M.A.P. Rebelo
Disciplina de N efrologia, Hospital U niversitário Pedro Ernesto, Universidade do Estado do Rio de Janeiro, Rio de Janeiro, RJ, Brasil

\section{Correspondence}

N.C. Araújo

Rua São Salvador, 14/1404

22231-130 Rio de Janeiro, RJ

Brasil

Fax: + 55-21-285-5175

E-mail: nordeval@ ruralrj.com.br

Received May 22, 1998

Accepted December 17, 1999

\begin{abstract}
Hypocitraturia (HCit) is one of the most remarkable features of renal tubular acidosis, but an acidification defect is not seen in the majority of hypocitraturic patients, whose disease is denoted idiopathic hypocitraturia. In order to assess the integrity of urinary acidification mechanisms in hypocitraturic idiopathic calcium stone formers, we studied two groups of patients, hypocitraturic ( $\mathrm{HCit}, \mathrm{N}=21,39.5 \pm$ 11.5 years, 11 females and 10 males) and normocitraturic (NCit, $\mathrm{N}=$ 23, $40.2 \pm 11.7$ years, 16 females and 7 males) subjects, during a short ammonium chloride loading test lasting $8 \mathrm{~h}$. During the baseline period HCit patients showed significantly higher levels of titratable acid (TA). After the administration of ammonium chloride, mean urinary $\mathrm{pH}$ (3rd to 8th hour) and TA and ammonium excretion did not differ significantly between groups. Conversely, during the first hour mean urinary $\mathrm{pH}$ was lower and TA and ammonium excretion was higher in HCit. The enhanced TA excretion by HCit during the baseline period and during the first hour suggests that the phosphate buffer mechanism is activated. The earlier response in ammonium excretion by HCit further supports other evidence that acidification mechanisms react promptly. The present results suggest that in the course of lithiasic disease, hypocitraturia coexists with subtle changes in the excretion of hydrogen ions in basal situations.
\end{abstract}

\section{Introduction}

Urinary acidification defects are not rare among patients with urinary lithiasis. Initially, only cases of distal renal tubular acidosis were reported but later it was established that the proximal form was also associated with lithiasis (1-4). The incidence of this kind of disturbance varies considerably ( 3 to $25 \%$ ) according to the series studied (1$3,5-8)$. Studies in which both distal and proximal tubules were evaluated have yielded the highest percentages $(1,8)$. Hypocitraturia
Key words

- U rinary acidification

- Hypocitraturia

- Titratable acidity

- Ammonium

- Ammonium chloride

load test

- Lithiasis
(HCit) is one of the most marked characteristics of distal tubular acidosis both in its complete (9) and incomplete (10) forms. However, most cases of hypocitraturia are not accompanied by an acidification defect, corresponding to what is called idiopathic hypocitraturia (11). According to Pak (11), a diet rich in sodium or animal protein or a reduction in the gastrointestinal absorption of alkalis can be determining factors of hypocitraturia. Available studies about urinary acidification in lithiasic patients are more concerned with correlating acidifica- 
tion defects with renal hypercalciuria $(4,10$, 12) and with associating the presence of the acidification defect with higher morbidity (1), without mentioning the urinary excretion of citrate. Therefore, a well-conducted study concerning urinary acidification in patients with idiopathic hypocitraturia is lacking. The objective of the present study was to evaluate the integrity of the urinary acidification mechanism in patients with hypocitraturia who are idiopathic calcium stone formers.

\section{Subjects and Methods}

Among the patients evaluated at the clinic of Hospital Universitário Pedro Ernesto (HUPE), we selected those for whom the secondary causes for lithiasis (hyperparathyroidism, cystinuria, renal tubular acidosis, hyperoxaluria, gout, sarcoidosis, chronic diarrhea, etc.) as well as the complications of lithiasic illness (infection, hydronephrosis) could be excluded, and who had completed a routine investigation of metabolism following a protocol described elsewhere (13). We then tested these selected patients for urinary acidification with ammonium chloride at the dose of $0.1 \mathrm{~g} / \mathrm{kg}$ body weight. Two groups were studied, one with HCit (urinary citrate $<320 \mathrm{mg} / 24 \mathrm{~h} ; \mathrm{N}=21,39.5 \pm 11.5$ years, 11 females and 10 males) and the other with normocitraturia (NCit, urinary citrate $\geq 320 \mathrm{mg} / 24 \mathrm{~h} ; \mathrm{N}=23,40.2 \pm 11.7$ years, 16 females and 7 males). Initially, a basal urine sample was taken and arterial blood gases were analyzed. The corresponding dose of ammonium chloride was then administered and urine samples were taken eight times per hour. In order to keep urinary flow adequate, each patient was given 150 $\mathrm{ml}$ of water every hour, as recommended by Wrong and Davies (14). Those patients whose urinary $\mathrm{pH}$ was not reduced to 5.3 or less on average in the samples taken from the third to the eighth hour after drug administration were excluded from the study. At the end of the fourth hour a new arterial blood gas analysis was performed to ensure that the drug had been effective in producing a state of acidosis. pH, titratable acidity (TA) and ammonium (Am) (15) were measured in the basal sample and in every sample after the $\mathrm{NH}_{4} \mathrm{Cl}$ administration. The results are reported as mean $\pm \mathrm{SD}$. The difference between groups were determined by the unpaired Student $t$-test and the response of each group to ammonium chloride was evaluated by the paired Student $t$-test. The level of significance was set at $\mathrm{P}<0.05$.

\section{Results}

There was no difference between groups in terms of the dose of ammonium chloride administered $(\mathrm{HCit}=6.42 \pm 1.18 \mathrm{~g} v \mathrm{sCit}=$ $6.33 \pm 0.08 \mathrm{~g} ; \mathrm{P}>0.05)$. The two groups absorbed and metabolized the drug well as can be observed by the drop in blood $\mathrm{pH}$ and plasma bicarbonate in the blood gas analysis performed $4 \mathrm{~h}$ after the intake of ammonium chloride (Table 1).

Mean $\mathrm{pH}$, ammonium and titratable acidity excretion in samples obtained from the 3rd to the 8th hour did not differ between groups (Table 1).

The hourly analysis of the urinary $\mathrm{pH}$ curve (Figure 1A) shows that both groups started off from a comparable mean value that increased during the first hour, followed by a drop. There was a significant rise in $\mathrm{pH}$ in the NCit group during the first hour. This rise also occurred in the HCit group, but was not statistically significant. Thus, mean $\mathrm{pH}$ was lower in the HCit group during the first hour $(\mathrm{P}<0.05)$. From the second hour to the end of the test, there was a significant and similar fall in $\mathrm{pH}$ in both groups $(\mathrm{P}>0.05)$.

Titratable acidity fell significantly during the first hour in both groups $(\mathrm{P}<0.05)$. From the second hour on, however, there was a rise which continued until the end of the test (Figure 1B). Comparison of the hourly means revealed that the HCit group excreted 
more TA during the control hour and during the first hour after the ingestion of $\mathrm{NH}_{4} \mathrm{Cl}$ $(\mathrm{P}<0.05)$ but not during the subsequent hours $(\mathrm{P}>0.05)$. The increase (mean minus basal) in the excretion of titratable acidity was greater in the NCit group $(\mathrm{P}<0.05)$ (Table 1).

The same analysis for ammonium chloride revealed that after $\mathrm{NH}_{4} \mathrm{Cl}$ intake there was a rise in excretion which was already significant for the HCit group during the first hour $(\mathrm{P}<0.05)$ and in the NCit group from the second hour on $(\mathrm{P}<0.05)$ (Figure $1 \mathrm{C}$ ). Comparison of the hourly means showed greater excretion in the HCit group only during the first hour $(\mathrm{P}<0.05)$.

In Table 2, the values of urinary TA excretion for the HCit group in the basal state observed in the present study are among the highest reported in the literature, both for normal individuals and for stoneforming patients. Heilberg et al. (16) reported lower basal TA values than ours in patients with hypocitraturia. However, they included cases of urinary $\mathrm{pH}$ higher than 5.3 after an overload of $\mathrm{NH}_{4} \mathrm{Cl}$. In the work by Wrong and Davies (14), TA excretion after ammonium chloride stimulus was higher than in our study, although their group consisted of only 3 lithiasic patients (Table 2). In comparison to the values reported for normal individuals, the TA excretion of our patients after the ammonium chloride stimulus was situated in an intermediate position (Table 2).

Twenty-four-hour phosphate excretion was similar in both groups (Table 1).

\section{Discussion}

The basic mechanism that determines hypocitraturia is an increase in the tubular absorption of citrate, a situation mainly occurring in the presence of acidosis. However, in most cases of hypocitraturia there is no systemic acidosis and the mechanism of acidification, based on urinary $\mathrm{pH}$, is supposed to be intact. Experimental studies re- veal that in the case of chronic acidosis the mechanisms of urinary acidification are more active (17). It is known that in the incomplete form of distal renal tubular acidosis the exaggerate or normal excretion of ammonium prevents the appearance of acidemia, although hypocitraturia is already present. There is evidence that the incomplete form of renal tubular acidosis is an early stage of the complete form. We do not know whether there is an earlier stage. An acidification defect has not been found in most patients with hypocitraturic lithiasis (18), indicating that individuals can excrete urine with a $\mathrm{pH}$ equal to or lower than 5.3, which constitutes what is known as idiopathic hypocitraturia (11). According to Battle et al. (19), the capacity to excrete urine with a $\mathrm{pH}$ of 5.3 does not necessarily mean an intact process of hydrogen secretion through the distal tubule. In the present study, we assessed the excretion of hydrogen ions by determining

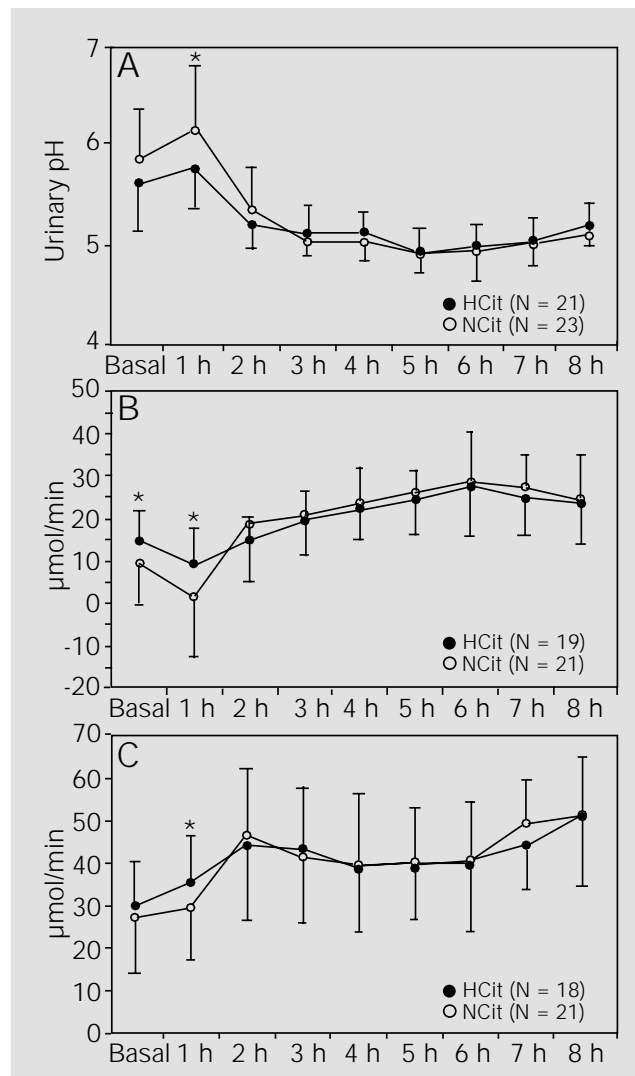

Figure 1 - Effect of ammonium chloride administration on urinary $\mathrm{pH}(\mathrm{A})$, titratable acidity $(\mathrm{B})$, and ammonium excretion (C) by patients with hypocitraturia (filled circles) and normocitraturia (blank circles). Data are reported as means \pm SD for $18-23$ measurements for each group. $* \mathrm{P}<0.05$ (Student t-test). 
the $\mathrm{pH}$ and $\mathrm{TA}$ and ammonium levels.

The present results show that hypocitraturic patients excrete more titratable acidity in the basal sample and during the first hour. It is known that titratable acidity basically depends on the $\mathrm{pK}$ of the buffer, on the availability of the buffer and on the urine $\mathrm{pH}$ (20). Since the HCit group displayed a lower urinary $\mathrm{pH}$ during the first hour, it was expected to excrete more TA exactly during the same hour, as was indeed the case. The inverse correlation between urinary $\mathrm{pH}$ and

Table 1 - Effect of $\mathrm{NH}_{4} \mathrm{Cl}$ in blood and urinary chemistry.

Values are reported as mean $\pm \mathrm{SD} . * \mathrm{P}<0.054 \mathrm{~h}$ or mean vs basal (paired Student t-test); $* * \mathrm{P}<0.05$ HCit vs NCit (unpaired Student t-test). HCit, Hypocitraturia; NCit, normocitraturia; TA, titratable acidity; Am, ammonium.

\begin{tabular}{lcccccc}
\hline Parameter & Citrate & Basal & $4 \mathrm{~h}$ & Mean $(3-8 \mathrm{~h})$ & Mean minus basal & Urine (24 h) \\
\hline Blood pH & HCit & $7.41 \pm 0.04$ & $7.34 \pm 0.04^{*}$ & - & - & - \\
& NCit & $7.42 \pm 0.04$ & $7.35 \pm 0.05^{*}$ & - & - & - \\
Blood HCO 3 & HCit & $24.4 \pm 3.11$ & $19.4 \pm 2.29^{*}$ & - & - & - \\
$(\mathrm{mEq} / \mathrm{l})$ & $\mathrm{NCit}$ & $24.9 \pm 2.23$ & $18.7 \pm 3.04^{*}$ & - & - & - \\
Urinary pH & $\mathrm{HCit}$ & $5.63 \pm 0.48$ & - & $5.07 \pm 0.18^{*}$ & - & - \\
& $\mathrm{NCit}$ & $5.87 \pm 0.49$ & - & $5.01 \pm 0.3^{*}$ & - & - \\
$\mathrm{TA}(\mu \mathrm{Mol} / \mathrm{min})$ & $\mathrm{HCit}$ & $17.6 \pm 7.6$ & - & $26.6 \pm 7.1^{*}$ & $9.01 \pm 6.24$ & - \\
& $\mathrm{NCit}$ & $9.4 \pm 8.8^{* *}$ & - & $26.1 \pm 7.8^{*}$ & $16.5 \pm 9.11^{* *}$ & - \\
Am $(\mu \mathrm{Mol} / \mathrm{min})$ & $\mathrm{HCit}$ & $29.8 \pm 10.5$ & - & $45.5 \pm 9.2^{*}$ & - & - \\
& $\mathrm{NCit}$ & $27.1 \pm 12.9$ & - & $45.4 \pm 12.7^{*}$ & - & - \\
Urine phosphate & HCit & - & - & - & - & $443 \pm 171$ \\
$(\mathrm{mg} / 24 \mathrm{~h})$ & $\mathrm{NCit}$ & - & - & - & - & $510 \pm 219$
\end{tabular}

Table 2 - Titratable acidity (TA) and ammonium (Am) excretion in the basal state and after $\mathrm{NH}_{4} \mathrm{Cl}$ administration.

*Backman et al. used a dose of $0.2 \mathrm{~g} / \mathrm{kg}$ of $\mathrm{NH}_{4} \mathrm{Cl}$. In the other studies a dose of $0.1 \mathrm{~g} / \mathrm{kg}$ was used. HUPE, Hospital Universitário Pedro Ernesto; HCit, hypocitraturia; NCit, normocitraturia.

\begin{tabular}{lcccccccc}
\hline References & $\mathrm{N}$ & $\begin{array}{c}\text { Baseline } \\
\mathrm{TA}\end{array}$ & $\begin{array}{c}\mathrm{NH}_{4} \mathrm{Cl} \\
\mathrm{TA}\end{array}$ & $\begin{array}{c}\text { Baseline } \\
\mathrm{Am}\end{array}$ & $\begin{array}{c}\mathrm{NH}_{4} \mathrm{Cl} \\
\mathrm{Am}\end{array}$ & Unit & $\begin{array}{c}\text { Baseline } \\
\mathrm{pH}\end{array}$ & $\begin{array}{c}\mathrm{NH}_{4} \mathrm{Cl} \\
\mathrm{pH}\end{array}$ \\
\hline Normals & & & & & & & & \\
$\quad 4$ & 7 & - & - & - & 55.0 & $\mu \mathrm{Eq} / \mathrm{min}$ & - & 5.00 \\
14 & 10 & - & 37.9 & - & 50.4 & $\mu \mathrm{Eq} / \mathrm{min}$ & - & 4.81 \\
16 & 10 & 10.9 & 38.8 & 28.3 & 51.5 & $\mu \mathrm{Eq} / \mathrm{min}$ & 6.30 & 5.50 \\
22 & 17 & 8.0 & - & 37.1 & - & $\mu \mathrm{Eq} / \mathrm{min}$ & 5.51 & - \\
23 & 10 & - & 37.9 & - & 52.8 & $\mu \mathrm{Eq} / \mathrm{min}$ & - & 5.00 \\
24 & 5 & 13.0 & 25.0 & 20.0 & 33.0 & $\mu \mathrm{Eq} / \mathrm{min}$ & 5.41 & 4.83 \\
Kidney stone formin & & & & & & & & \\
12 & 26 & 10.0 & - & 23.0 & - & $\mu \mathrm{Eq} \mathrm{kg}-1 / \mathrm{h}^{-1}$ & - & - \\
14 & 3 & - & 45.0 & - & 46.7 & $\mu \mathrm{Eq} / \mathrm{min}$ & - & 4.85 \\
16 & 15 & 8.6 & 22.5 & 21.9 & 48.1 & $\mu \mathrm{Eq} / \mathrm{min}$ & 6.40 & 5.40 \\
$25 *$ & 39 & - & 29.0 & - & 62.0 & $\mu \mathrm{Eq} / \mathrm{min}$ & - & 4.80 \\
HUPE, HCit & 18 & 17.6 & 26.6 & 29.8 & 45.5 & $\mu \mathrm{Eq} / \mathrm{min}$ & 5.63 & 5.07 \\
HUPE, NCit & 21 & 9.4 & 26.1 & 27.1 & 45.4 & $\mu \mathrm{Eq} / \mathrm{min}$ & 5.87 & 5.01 \\
& & & & & & & &
\end{tabular}


phosphate-dependent excretion of titratable acidity only occurs at $\mathrm{pH}$ ranges equal to or higher than 5.5. Due to the pK of phosphate (6.8), when the $\mathrm{pH}$ is lower than 5.5 almost all dibasic phosphate $\left(\mathrm{HPO}_{4}{ }^{2-}\right)$ has been transformed into monobasic phosphate $\left(\mathrm{H}_{2} \mathrm{PO}_{4}{ }^{-}\right)$ and the buffering ceases unless there is an increase in phosphate excretion. The higher TA excretion in the HCit group in the basal situation in which the urinary $\mathrm{pH}$ was equivalent in the two groups suggests a greater availability of phosphate buffer during this hour. A greater availability of phosphate early in the morning after the night abstinence from food suggests that this difference is not due to an acute effect of diet. Twentyfour-hour phosphate excretion was similar in both groups (Table 1), suggesting that the difference in TA cannot be attributed to phosphate. However, some peculiarities of the circadian rhythm of phosphate do not totally rule out the possibility of phosphate contributing to a greater excretion of TA. Serum phosphate presents a circadian rhythm that reaches a peak in the early hours and a maximum fall at around 10:00 a.m.; coincidentally, urinary phosphate excretion is lower between 7:00 and 10:00 a.m. than during the other $21 \mathrm{~h}$ of the day (21). Therefore, although 24-h urinary phosphate excretion did not differ between the two groups of patients, we cannot rule out a difference in segments of the daily excretion curve in our patients. The time of 10:00 $\mathrm{h}$ in the morning also coincided with the drop in titratable acidity excretion experienced by both groups right after the intake of ammonium chloride, which was nevertheless lower in the HCit group. It may be assumed that in the HCit group this drop was attenuated by a higher excretion of titratable acidity in the basal samples of the circadian rhythm, which could justify a higher excretion of titratable acidity in the samples during the first hour. The origin of phosphate may correspond to a chronic effect of diet or even to bone, although this possibility is merely speculative. After the first hour of the $\mathrm{NH}_{4} \mathrm{Cl}$ intake it is no longer detected a difference in the excretion of TA or in the urinary $\mathrm{pH}$ between the two groups.

The NCit group, starting from a lower basal value of TA, was more capable of increasing the excretion of titratable acidity than the HCit group, suggesting that in the latter group the process of activation was already close to the saturation point. Mean ammonium excretion was equal in both groups. However, the HCit group presented an early response in terms of ammonium excretion, supporting the idea that acidification mechanisms are hyper-reactive, as observed in the chronic acidosis situation. The test demonstrated that the HCit group excreted an important part of the acid load during the first hour while in the NCit group this phenomenon occurred later. It is most probable that this phenomenon reflects a chronic effect of diet in hypocitraturic patients. It is known that in hypocitraturia with normal urinary acidification the factors involved are a diet rich in sodium or animal protein or a reduction in the gastrointestinal absorption of alkalis (11).

The results obtained here suggest that in the course of lithiasic disease, hypocitraturia coexists with subtle changes in the excretion of hydrogen ions in basal situations, possibly representing the earlier feature of an acidification defect that precedes incomplete distal renal tubular acidosis. A further follow-up study is required to assess if these patients will show one of the forms of distal renal tubular acidosis in the future. 


\section{References}

1. Backman U, Danielson BG, J ohansson G, Ljunghall S \& Wilkström B (1990). Incidence and clinical importance of renal tubular defects in recurrent renal stone formers. Nephron, 25: 96-101.

2. Cintron-Nadal E, Lespier LE, RomanMiranda A \& Martinez-Maldonado M (1977). Renal acidifying ability in subjects with recurrent stone formation. J oumal of Urology, 118: 704-706.

3. Surian $M$, Malberti $F$, Cosci $P$, Corradi $B$, Colussi G, De Ferrari ME, Poggi M, Luini A \& Mineti L (1987). Renal tubular acidosis in recurrent calcium nephrolithiasis. Contributions to Nephrology, 58: 44-48.

4. Tessitore N, Ortalda V, Fabris A, D'Angelo A, Rugiu C, Oldrizzi L, Lupo A, Valvo E, Gammaro L, Loschiavo C, Panzetta G, Panebianco R, Bedogna V \& Maschio $G$ (1985). Renal acidification defects in patients with recurrent calcium nephrolithiasis. Nephron, 141: 325-332.

5. Antón FM, Puig GJ , Gaspar G, Martínez ME, Ramos T \& Martínez Piñeiro JÁ (1984). Renal tubular acidosis in recurrent renal stone formers. European Urology, 10: 55-59.

6. Backman U, Danielson BG \& Sohtell M (1976). Urine acidification capacity in renal stone formers. Scandinavian J ournal of Urology and Nephrology, 35 (Suppl): 49-61.

7. Cochran $M$, Peacock $M$, Smith DA \& Nordin BEC (1968). Renal tubular acidosis of pyelonephritis with renal stone disease. British Medical J ournal, 2: 721-729.

8. Fellström B, Backman U, Danielson BG, J ohansson $G$, Ljunghall $S \&$ Wilkström $B$
(1982). Urinary excretion of urate in renal calcium stone disease and in renal tubular acidification disturbances. J ournal of Urology, 127: 589-592.

9. Norman ME, Feldman NI, Cohn RM, Roth KS \& McCurdy DK (1978). Urinary citrate excretion in the diagnosis of distal renal tubular acidosis. J ournal of Pediatrics, 92: 394-400.

10. Konnak J W, Kogan BA \& Lau K (1982). Renal calculi associated with incomplete distal renal tubular acidosis. J oumal of Urology, 128: 900-902.

11. Pak CYC (1991). Citrate and renal calculi: new insights and future directions. American J ournal of Kidney Diseases, XVII: 420425.

12. Nutahara K, Higashihara E, Yasunori I \& Niijima T (1989). Renal hypercalciuria and acidification defect in kidney stone patients. J ournal of Urology, 141: 813-818.

13. Levy FL, Adams-Huet B \& Pak CYC (1995). Ambulatory evaluation of nephrolithiasis: an update of a 1980 protocol. American J ournal of Medicine, 98: 50-59.

14. Wrong $\mathrm{O} \&$ Davies HEF (1959). The excretion of acid in renal disease. Quarterly J ournal of Medicine, 110: 259-313.

15. Chan J CM (1972). The rapid determination of urinary titratable acid and ammonium and evaluation of freezing as a method of preservation. Clinical Biochemistry, 5: 94-98.

16. Heilberg IP, Velasco ROP, Moreira SRS \& Schor N (1995). Provas de acidificação urinária. In: Schor N \& Heilberg IP (Editors), Calculose Renal - Fisiopatologia, Diagnóstico e Tratamento. Sarvier, São Pau- lo, $158-160$.

17. Pitts RF (1948). The renal excretion of acid. Federation Proceedings, 7: 418-426.

18. Nicar MJ , Skurla C, Sakhaee K \& Pak CYC (1983). Low urinary citrate excretion in nephrolithiasis. Urology, 1: 8-14.

19. Battle D, Grupp M, Gaviria M \& Kurtzman NA (1982). Distal renal tubular acidosis with intact capacity to lower urinary $\mathrm{pH}$. American J ournal of Medicine, 72: 751758.

20. Simpson DP (1971). Control of hydrogen ion homeostase and renal acidosis. Medicine, 50: 503-541.

21. Borghi L, Elia GF, Trapassi MR, Barbarese $F$, Melloni E, Amato F, Guerra A \& Novarini A (1987). Urinary composition in normal men on usual diet and life-style. Contributions to Nephrology, 58: 21-24.

22. Tannen RL (1971). The response of normal subjects to the short ammonium chloride test: the modifying influence of renal ammonia production. Clinical Science, 41: 583-595.

23. Falls J r WF (1972). Comparison of urinary acidification and ammonium excretion in normal and gouty subjects. Metabolism, 21: 433-445.

24. Oster J R, Hotchkiss J L, Carbon M, Farmer M \& Vaamonde CA (1975). A short duration renal acidification test using calcium chloride. Nephron, 14: 281-292.

25. Backman U, Danielson BG \& Sohtell M (1976). A short duration renal acidification test. Scandinavian J ournal of Urology and Nephrology, 35 (Suppl): 33-49. 